\title{
Tratamiento de una herida quirúrgica próxima a una fístula arteriovenosa con aquacel Ag@
}

\author{
Carmen Rodríguez Gonzálvez* - María Eugenia Canals Asuar* - Joaquín De Juan Ribera**
}

\section{Clínica de Hemodiálisis ASHDO. Elche (Alicante) - *Enfermera - **Nefrólogo}

\section{Introducción}

Los pacientes en hemodiálisis precisan un acceso vascular en óptimas condiciones para una hemodiálisis eficiente. Pero es una realidad el hecho de que, desde el inicio de la patología renal en un individuo, el árbol venoso recibe múltiples castigos debido a extracciones sanguíneas, pruebas terapéuticas, y accesos vasculares múltiples, tras previos fallidos. En algunos casos, cuando el acceso presenta dificultades de punción y canalización ${ }^{1,2}$, está indicado realizar una superficialización del vaso, frecuentemente la vena basílica, que consiste en liberar la vena del interior de la aponeurosis braquial, prosiguiendo con su posterior exteriorización, haciéndola más accesible. Algunas de las complicaciones de esta intervención son los problemas en la cicatrización, la necrosis de bordes de la herida, e infección².

\section{Resumen historia clínica}

En nuestro Centro de Hemodiálisis ASHDO de EIche, un centro concertado con el Servicio Valenciano de Salud, nos encontramos ante un caso de complicación en la superficialización de un acceso vascular. El sujeto era un varón hipertenso, con há-

\author{
Correspondencia: \\ Carmen Rodríguez Gonzálvez \\ Clínica de Hemodiálisis ASHDO \\ C/ Fray Pedro Balaguer 63 \\ 03202. Elche \\ alalbadehoy@hotmail.com
}

bito tabáquico, VHC, e IRC secundaria a reflujo y agenesia renal izquierda. Inició hemodiálisis en 1992. Fue trasplantado en 1994 y volvió a hemodiálisis en 2001 . Realizaba 4 sesiones de HD semanales de manera habitual. Tras ruptura de aneurisma del último acceso funcionante (FAVI humero cefálica izquierda), se le realizó una nueva FAVI radio cefálica en miembro superior derecho que no funcionó, y posteriormente otra humero basílica. Durante todo el período que duró el proceso de maduración de éstas, fue portador de hasta cinco diferentes catéteres (cuatro femorales y uno subclavio) que eran sustituidos unos por otros debido a problemas de función o infección.

Siendo portador del último catéter femoral, en noviembre de 2006 se le practicó una superficialización de la FAVI humero basílica derecha tras presentar problemas de punción, que cursó con una complicación hemorrágica importante. A los siete días de la superficialización presentaba dehiscencia de bordes de $5,5 \mathrm{~cm}$ de longitud, y $1,5 \mathrm{~cm}$ de anchura, con presencia de exudado maloliente, e intenso dolor. El paciente llevaba cobertura antibiótica 11 días antes de la superficialización por infección de orificio del catéter femoral, con lgr de vancomicina cada cinco días hasta un total de 4 dosis. Tras complicación en la superficialización, se prolongó el tratamiento antibiótico con lgr de vancomicina hasta un total de 11 dosis, y se pautó al mismo tiempo tobramicina lgr por sesión, hasta un total de 18 dosis.

Las curas se efectuaban limpiando por arrastre con suero fisiológico y tras secar, se aplicaba povidona yodada; a continuación se cubría la herida con gasas y 
un vendaje de sujeción. Debido a que la evolución de la herida no era favorable, decidimos introducir un cambio en las curas. El cambio consistió en sustituir el antiséptico utilizado hasta ese momento por clorhexidina al 2\%, y aplicar apósitos con tecnología hidrofiber, Aquacel $\mathrm{Ag} \AA \mathrm{Cu}-$ briendo únicamente la zona dehiscente de la herida quirúrgica, y colocando gasas en el resto de la misma, de acuerdo a las indicaciones para este producto ${ }^{3}$.

El Aquacel $\mathrm{Ag} \circledast$ es un apósito absorbente antimicrobiano, con impregnación argéntica, blando, estéril, no tejido, en forma de almohadilla, con plata iónica. La plata destruye un amplio espectro de bacterias de la lesión y crea un ambiente antimicrobiano. El apósito absorbe grandes cantidades de exudado y bacterias, formando un gel blando y cohesivo que se adapta perfectamente a la superficie de la misma manteniendo la humedad y ayudando a eliminar el tejido necrótico (desbridamiento autolítico). El ambiente húmedo de la lesión y el control del número de bacterias contribuyen al proceso de cicatrización, y ayudan a disminuir el riesgo de infección. Está indicado en úlceras vasculares y úlceras por presión, en ambos casos infectadas, con elevado riesgo de infección o con contaminación bacteriana.

El modo de uso según las indicaciones técnicas del producto es el siguiente: en las lesiones secas se coloca el apósito humedeciéndolo con solución salina estéril; para la lesión húmeda se procede a la limpieza de la herida y la posterior colocación del apósito. En ambos casos debe sobrepasar al menos $1 \mathrm{~cm}$ la zona lesionada.

En nuestro caso se utilizaron apósitos Aquacel $\mathrm{Ag}{ }^{\circledR}$ (figura 1) como base de tratamiento de las curas, ya que estaban indicados en heridas quirúrgicas como la que nos enfrentábamos ${ }^{4,5}$ Como antiséptico se usó clorhexidina $2 \%$ en spray. Según las guías de la $\mathrm{SEN}^{6}$, el acceso vascular se debe limpiar con antiséptico previo a su uso, pero no especifica cuál. Para los catéteres, indican como antiséptico de elección la clorhexidina al $2 \%$ debido a que la povidona yodada al $10 \%$ precisa 3 minutos para ejercer su acción, es bacteriostática, y ha demostrado ser perjudicial para el catéter, llegando a corroerlo hasta la rotura. De modo que como el antiséptico que se usaba para el catéter era la clorhexidina $2 \%$, decidimos utilizarlo también para las curas de la herida. Los instrumentos que se usaron para ha- cer un seguimiento de la herida en cada sesión fueron una cámara fotográfica digital, y una regla de $40 \mathrm{~cm}$ para medir su longitud.

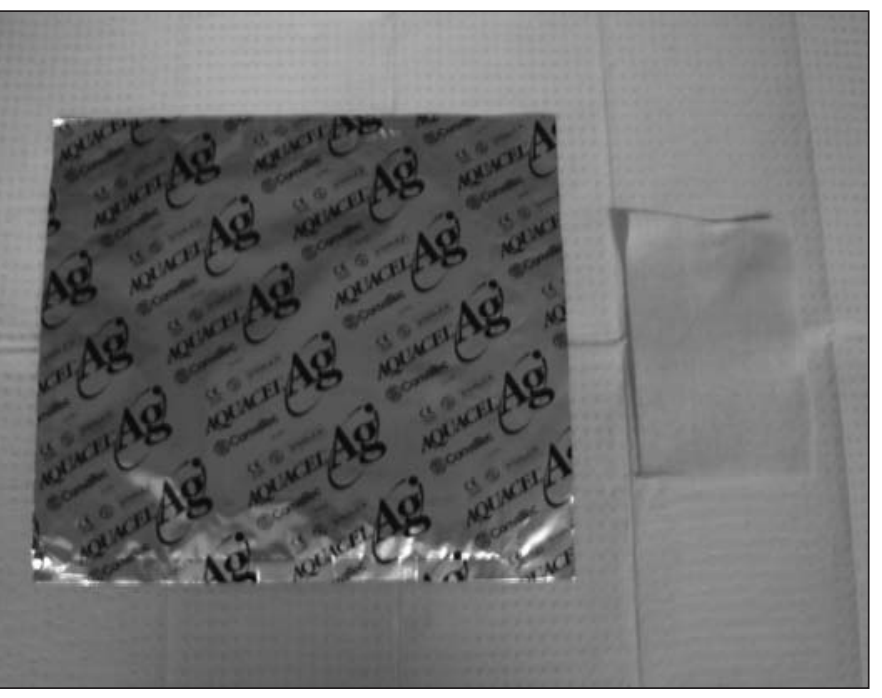

1: Apósito

En el momento que se instauraron las curas se llevaron a cabo las siguientes actividades:

- Seguimiento escrito de la evolución de la herida en cuanto a apariencia visual, longitud, presencia de olor y exudado, y aparición de hemorragia.

- Registro del método de cura y material utilizado para cada día. Se unificaron criterios para limpiar con suero fisiológico mediante arrastre las secreciones y material necrótico que se desprendía, después se aplicaba solución de clorhexidina $2 \%$ en spray, y a continuación el apósito.

- Se efectuaron fotografías periódicas para tener constancia de la evolución de la herida, y permitir comparaciones.

\section{Evolución}

Cuando iniciamos el tratamiento de curas con Aquacel $\mathrm{Ag}{ }^{\circledR}$ la herida quirúrgica presentaba sangrado moderado continuo y escaso olor con bordes dehiscentes y amarillos; el paciente refería dolor. Al día siguiente encontramos los apósitos con secreciones serohemáticas, menos abundantes que el día anterior, sin olor; los bordes continuaban amarillos y enrojecidos; la herida medía $6 \mathrm{~cm}$ de longitud, y 1,5 cm de ancho abarcando 5 puntos de sutura. 
El cuarto día desde el inicio del tratamiento se evidenció aumento de la cantidad de esfacelos; conforme fueron desapareciendo dejaron paso a tejido celular subcutáneo con revascularización. A los siete días la herida era 0,5 cm menor en longitud (figura 2). El día 11 los esfacelos habían desaparecido por completo, el color de la herida era de un rojo intenso, debido a la revascularización del lecho de la misma y a los pocos días se empezó a observar tejido de granulación. El día 18 se abrieron espontáneamente varios orificios a lo largo de los puntos de sutura de la herida quirúrgica en su porción proximal; al realizar la cura de rutina, se sospechó la presencia de hematoma sólido, y presionamos para drenarlo, con lo que se extrajeron grandes coágulos a través de los orificios e inmediatamente se apreció una reducción significativa de la induración que hasta ahora rodeaba la lesión; el paciente refirió una disminución notable del dolor y a partir de entonces se aplicó Aquacel $\mathrm{Ag}{ }^{\circledR}$ en toda la extensión de la sutura se introdujo una gasa en el orificio de mayor profundidad (figura 3 ). El día 21 se continuaban drenando los coágulos y la herida disminuía en longitud; en ese momento medía $4,5 \mathrm{~cm}$ de largo y $1 \mathrm{~cm}$ de ancho, presentando abundante tejido de granulación. El día 27 se observaba abundante tejido de granulación por todos los bordes de la herida; los orificios estaban cerrados y no era necesario introducir la gasa por lo que aplicamos el protocolo de cura para lecho seco. El día 35 el brazo estaba epitelizado, quedaba una pequeña costra en el lugar por donde drenaron los coágulos que se curó solamente con clorhexidina $2 \%$ y se dejó al aire consiguiéndose el día 40 una epitelización completa (figura 4).

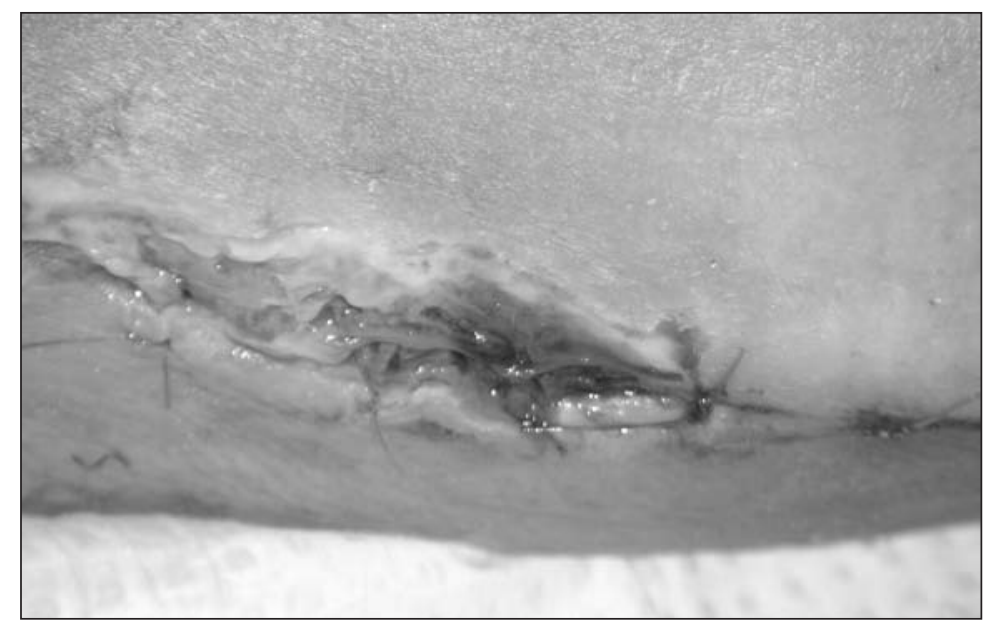

Figura 2: Herida a los 7 días

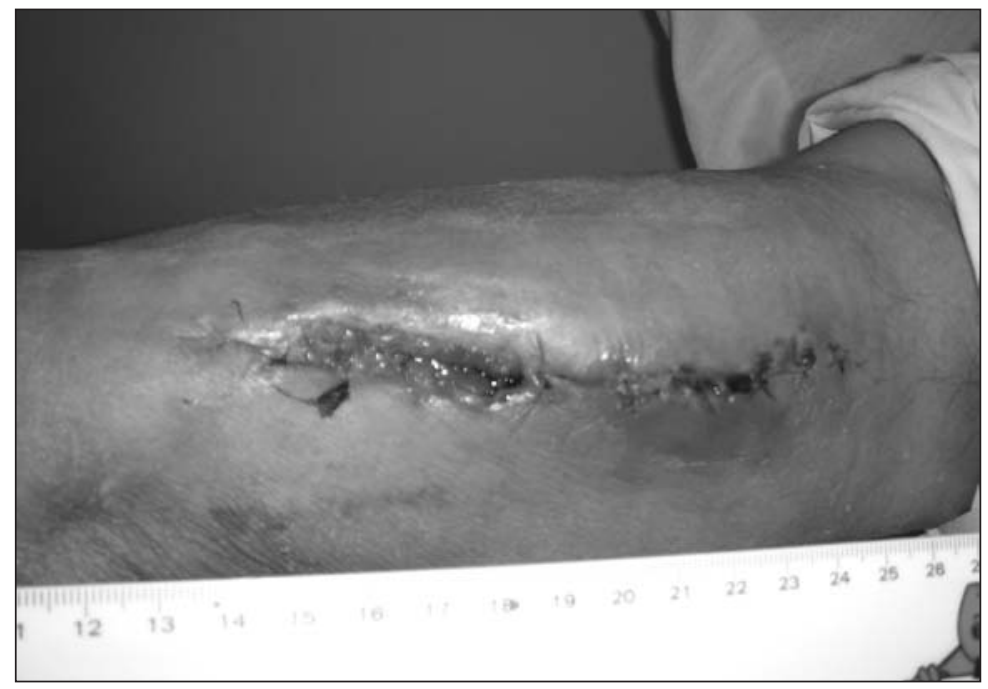

Figura 3: Herida a los 18 días

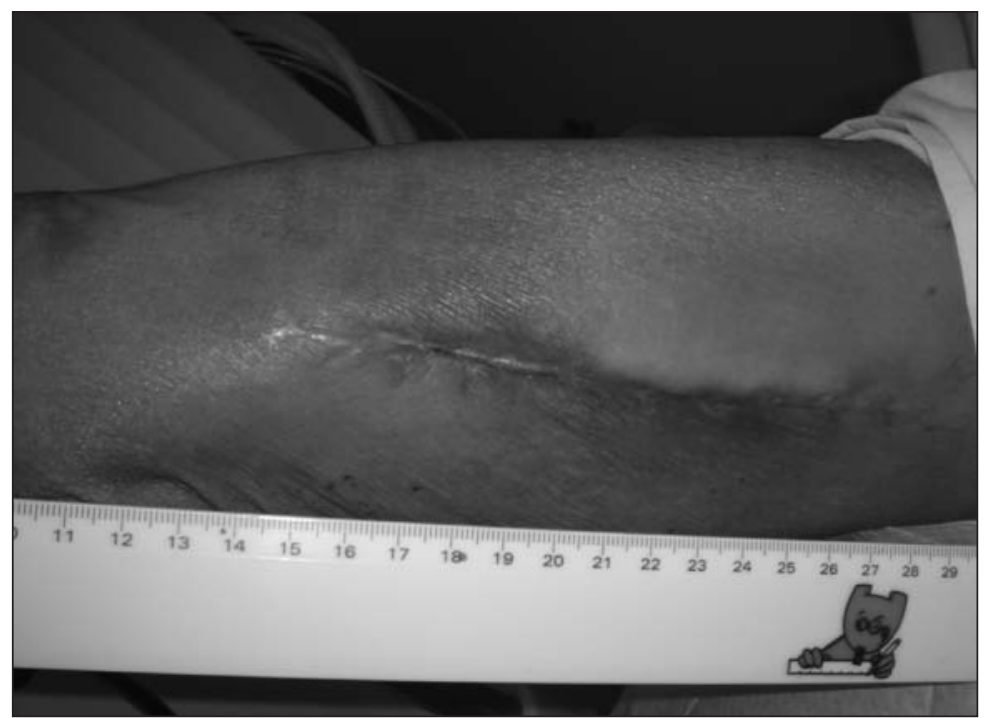

Figura 4: Epitelización completa a los 40 días 


\section{Conclusión}

La aplicación de Aquacel-Ag® en el tratamiento de esta herida quirúrgica próxima a una FAVI ha tenido efecto beneficioso en el paciente; por lo que para heridas de características similares podría ser más efectivo este tipo de tratamiento que el tratamiento convencional con suero fisiológico y povidona yodada.

\section{Agradecimientos}

A la doctora $\mathrm{M}^{\mathrm{a}}$ Dolores García Navarro, por sus consejos.

\section{Bibliografía}

1. A. Barreiro Mouro, M. Vicente Santiago. Técnicas alternativas a la fístula arteriovenosa de Brescia Cimino. Angiología 2005; 57 (supl 2):205-S209.

2. Pobo VJ, Sesma-Gutiérrez A, Viviens-Redondo B et al. Técnica quirúrgica, propiamente dicha, del acceso vascular autólogo. Angiología 2005; 57 (supl 2): 55-64.

3. Ficha técnica de Aquacel $A G \circledast .2004$

4. Lansdown AB, Williams $A$ et al. Silver absorption and antibacterial efficacy of silver dressings. J Wound Care. 2005 Apr; 14 (4): 155-60.

5. Jones SA, Bowler PG, et al. Controlling wound bioburden with a novel silver-containing Hydrofiber dressing. Wound Repair Regen. 2004 May-jun; 12(3): 288-94.

6. Guías de acceso vascular en hemodiálisis. Sociedad Española de Nefrología. 2004. 